\title{
Development of Biodegradable Isosaccharinate-Containing Foams for Decontamination of Actinides: Thermodynamic and Kinetic Reactions between Isosaccharinate and Actinides on Metal and Concrete Surfaces
}

EMSP Project 82715

\author{
Dhanpat Rai ${ }^{1}$, Linfeng $\mathrm{Rao}^{2}$, Robert C. Moore ${ }^{3}$, Ranko Bontchev ${ }^{3}$ \\ Kathleen Holt $^{3}$ \\ ${ }^{1}$ Pacific Northwest National Laboratory, Richland, WA \\ ${ }^{2}$ Lawrence Berkeley National Laboratory, Berkeley, CA \\ ${ }^{3}$ Sandia National Laboratories, Albuquerque, NM
}

\section{RESEARCH OBJECTIVE}

Actinide contamination of steel and concrete surfaces is a major problem within the DOE complex. Almost all current decontamination technologies rely on removal of the contaminated surface layer by mechanical means or by chemical methods using harsh chemicals. Some of the technologies are ineffective. Others are expensive, labor intensive, and hazardous to workers. Still others create secondary mixed wastes that are not environmentally acceptable. This project seeks fundamental information that will lead to the development of a new and more environmentally acceptable technology for decontamination of actinides, especially $\mathrm{Pu}$, on steel and concrete surfaces. The key component of this technology is isosaccharinate (ISA), a degradation product of cellulose materials that is biodegradable. Isosaccharinate will be incorporated into foams/gels for safe and easy use in decontamination of actinides from steel, concrete, and other surfaces. Thermodynamic data are being developed on ISA species as a function of $\mathrm{pH}$ and on ISA interactions with actinides and competing metals [e.g., Fe(III) and $\mathrm{Ca}(\mathrm{II})]$ under a wide range of conditions relevant to decontamination of steel and concrete. The efficiency of the ISA containing foams/gels/solutions for decontamination is also being tested. This project builds on capabilities at three different national laboratories, and represents a joint effort between PNNL, LBNL, and SNL.

\section{RESEARCH PROGRESS AND IMPLICATIONS}

This report summarizes the results of nearly three years of research. The past available data on ISA with tetravalent actinides have been very limited (limited to $\mathrm{pH} 12$ ), empirical, and only related to determining actinide behavior in cementitious environments. The emphasis of our work has been on developing fundamental data for ISA complexes to test its use/applicability for cleaning actinide contaminated surfaces and for cleaning surfaces contaminated with other radionuclides and non-radioactive elements. Although ISA forms strong complexes with actinides in all different oxidation states, the complexes with tetravalent actinides are of the highest interest. This is because actinides (especially $\mathrm{Pu}$ and $\mathrm{Th}$ ) are expected to be present in 
the tetravalent state, the state at which they are extremely insoluble and need to be removed for decontamination purposes. Therefore, a major emphasis of our fundamental studies on actinides has been on the actinides in the tetravalent state. For this purpose we are developing fundamental data on 1) ISA salts and its species as a function of $\mathrm{pH}, 2$ ) ISA comp lexes with tetravalent actinides, in particular Th(IV) and $\mathrm{Np}(\mathrm{IV})$, in the entire range of $\mathrm{pH}$ values of environmental interest, and 3) ISA complexes with metal ions (e.g., $\mathrm{Fe}(\mathrm{III}), \mathrm{Al}(\mathrm{III})$, and $\mathrm{Ca}(\mathrm{II})$ ) that compete with the actinides for ISA. In addition to fundamental studies, we are also conducting proof-of-principle decontamination tests and developing specifications for incorporation of ISA into decontaminating media (e.g., foams, gels). The progress made on these various research activities is briefly discussed below.

\section{Preparation of Ca and Na salts of ISA and NMR Characterization of ISA Species in solution}

Ca-ISA was prepared using the method developed by Whistler and BeMiller (1963) through the hydrolysis of a-lactose by $\mathrm{Ca}(\mathrm{OH})_{2}$. The Ca-ISA was purified by dissolution in $1 \mathrm{M}$ $\mathrm{HCl}$ followed by $\mathrm{pH}$ adjustment to 6.0 using $\mathrm{NaOH}$ and precipitation of $\mathrm{Ca}-\mathrm{ISA}$ with $\mathrm{CaCb}$.

Na-ISA was prepared by converting purified Ca-ISA using $\mathrm{Na}$ ? $\mathrm{Ca}$ ion exchange in a procedure similar to that reported by Glaus et al. (1999). In a typical reaction, $1 \mathrm{~g}$ Ca-ISA were mixed with $100 \mathrm{~g}$ of the sodium form of Chelax ion exchange resin. The mixture was stirred overnight using a rotary shaker and filtered through $0.5 \mu \mathrm{m}$ filter paper. XRD-pure crystalline $\mathrm{Na}$-ISA was isolated by slow evaporation of the remaining solution in a vacuum oven set at $40^{\circ} \mathrm{C}$ for 48 hours. Large Na-ISA crystals suitable for single crystal X-ray analysis were grown by slow evaporation of concentrated Na-ISA water solution at $60^{\circ} \mathrm{C}$ in air.

The purity of $\mathrm{Ca}$ - and Na-ISA was monitored mainly by powder X-Ray diffraction (XRD) using a Bruker D8 Advance instrument with monochromatized $\mathrm{Cu}-\mathrm{K}_{\alpha}$ radiation (Fig. 1). The observed low-speed scan XRD patterns of the starting Ca-ISA perfectly matched those reported by $\mathrm{Rai}^{2}$ and no impurity phases including $\mathrm{CaO}, \mathrm{Ca}(\mathrm{OH})_{2}$ and/or $\mathrm{CaCO}_{3}$ were detected within the method limitations (2-3\%). All lines in the powder XRD pattern of the Na-ISA product were indexed using the structural model and cell parameters described below and no impurity phases have been detected. The powder XRD patterns of the starting Ca-ISA and the Na-ISA product are compared in Fig. 1

Dilute aqueous solutions of the $\mathrm{Ca}$ and $\mathrm{Na}$ salts of " $\alpha$ "-D-isosaccharinate (ISA") have been analyzed by ${ }^{13} \mathrm{C}$ and ${ }^{1} \mathrm{H}$ NMR spectroscopy (Cho et al. 2003). The positions of the six ${ }^{13} \mathrm{C}$ ISA NMR lines show a $\mathrm{pH}$ dependence that can be used to infer that the most acidic proton is the one associated with the carboxylate group, with $\log \mathrm{K}^{0}$ of $-3.27 \pm 0.02$ for the reaction $\left[\mathrm{HISA}(\mathrm{aq}) \rightleftharpoons \mathrm{ISA}^{-}+\mathrm{H}^{+}\right]$. In acidic solutions $(\mathrm{pH}<\sim 4.5), \mathrm{NMR}$ signals were found that could be assigned to " $\alpha$ "-D-isosaccharino-1,4-lactone (ISL), formed from dehydration of isosaccharinic acid (HISA). These data provided fundamental information about the expected isosaccharinate species (Fig. 2) important in a wide range of $\mathrm{pH}$ values (1 to 14). 


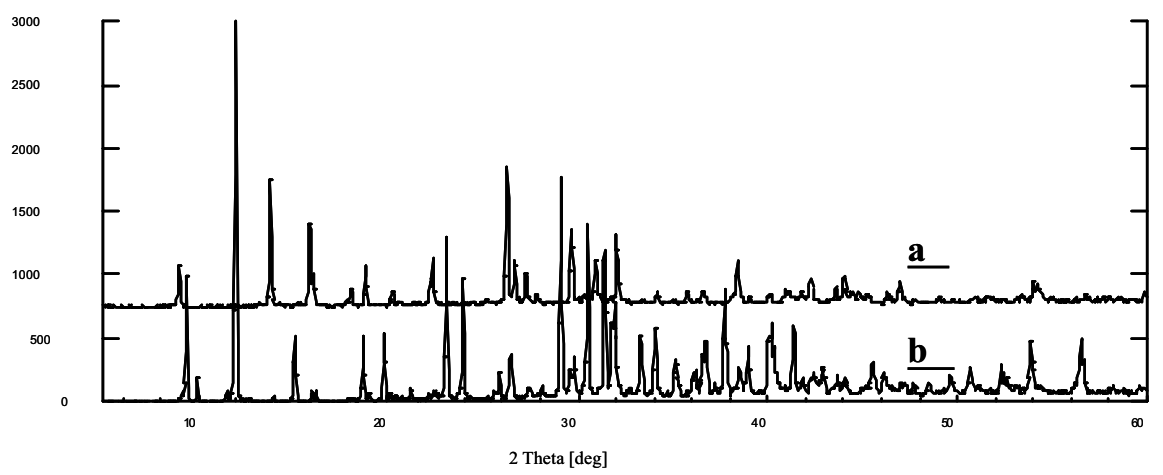

Fig. 1. XRD of sodium (a) and calcium (b) form of ISA

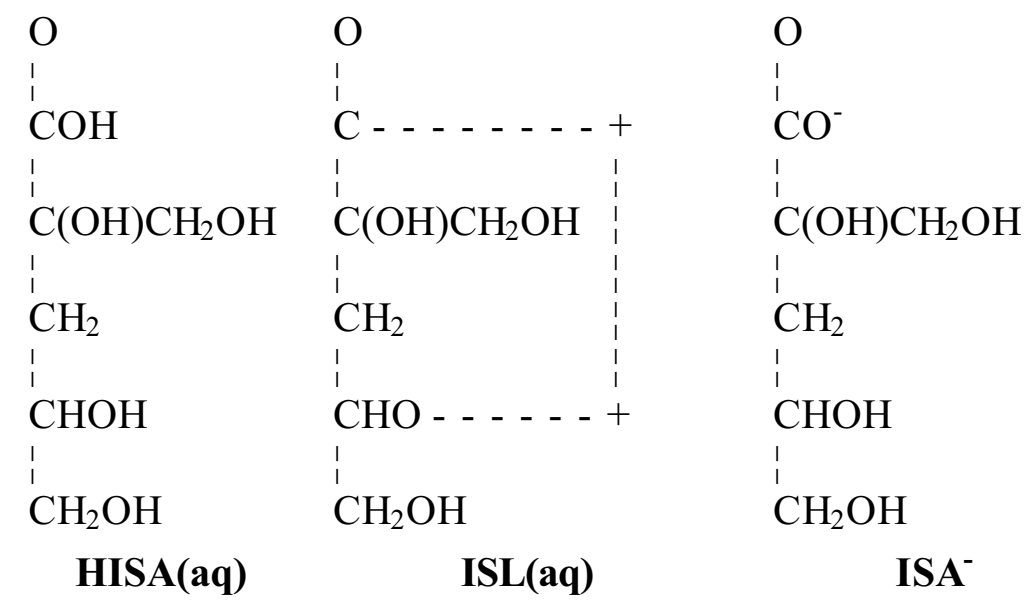

Fig. 2. Structures of organic ligands discussed in the paper: HISA(aq) ( $\alpha-D-$ isosaccharinic acid), ISL(aq) [ $\alpha$-D-isosaccharino-1,4-lactone, a product of dehydration of $\operatorname{HISA}(\mathrm{aq})]$, and $\operatorname{ISA}^{-}(\alpha-\mathrm{D}-$ isosaccharinate). 


\section{Isosaccharinate complexes with tetravalent actinides}

The solubility of $\mathrm{NpO}_{2}(\mathrm{am})$ as a function of $\mathrm{pH}$ at a fixed concentration of ISA shows that the observed aqueous Np concentrations are up to several orders of magnitude higher than expected in the absence of ISA. To further develop fundamental data, the solubility of $\mathrm{NpO}_{2}(\mathrm{am})$ was also determined as a function of ISA concentrations at a fixed $\mathrm{pH}$ of 12 . These data showed dramatic increases in solubility with the increase in ISA concentrations. When the solubility as a function of ISA concentrations at a fixed $\mathrm{pH}$ of 12 are compared with the concentrations at a fixed $\mathrm{pH}$ of 5 (Rai et al. 1998), the dramatic increases in Np concentrations are observed in most of the environmental range of $\mathrm{pH}$ values with the increase in ISA concentrations. A comprehensive thermodynamic model for system $\mathrm{Np}(\mathrm{IV})-\mathrm{Ca}^{2+}-\mathrm{Na}^{+}-\mathrm{H}^{+}-\mathrm{OH}^{-}-$ ISA $^{-}$was developed (Rai et al. 2003) based on the data obtained in this study and those reported in the literature. The model is based on studies of 1) the solubility of $\mathrm{Ca}(\mathrm{ISA})_{2}(\mathrm{c})$ and NMR investigations of HISA(aq) (isosaccharinic acid) and ISL(aq) (dehydration product of HISA(aq)) to determine the acid dissociation constant of HISA(aq), hydrolysis reaction of ISL(aq), and complexation constants of $\mathrm{Ca}^{2+}$ with ISA; 2) $\mathrm{NpO}_{2}(\mathrm{am})$ solubility in a wide range of $\mathrm{pH}$ values ( $\sim 2$ to 14 ) and total ISA concentrations of $0.0016 \mathrm{~m}$ and $0.008 \mathrm{~m}$, and at fixed $\mathrm{pH}$ values of approximately 5 and 12 with total ISA concentrations ranging from $0.0001 \mathrm{~m}$ to $0.1 \mathrm{~m}$ to determine equilibrium constants of various $\mathrm{Np}(\mathrm{IV})$-ISA complexes; and 3) solvent extraction of $\mathrm{Np}$-ISA solutions, containing fixed $\mathrm{NaClO}_{4}$ concentrations ranging from $0.103 \mathrm{~m}$ to $6.54 \mathrm{~m}$ and at fixed $\mathrm{p} C_{\mathrm{H}^{+}}$values ranging from 1.5 to 1.9 , with dibenzoylmethane to test/extend the model to high ionic strength and acidity. Pitzer's ion-interaction approach was used to interpret the data. The isosaccharinate complexes required to explain these data included $\mathrm{Ca}(\mathrm{ISA})^{+}$, $\mathrm{Np}(\mathrm{OH})_{3}(\mathrm{ISA})(\mathrm{aq}), \mathrm{Np}(\mathrm{OH})_{3}(\mathrm{ISA})_{2}{ }^{-}, \mathrm{Np}(\mathrm{OH})_{4}(\mathrm{ISA})^{-}$, and $\mathrm{Np}(\mathrm{OH})_{4}(\mathrm{ISA})_{2}{ }^{2-}$. The values of equilibrium constants for the complexes determined from these data (Table I) provided close agreement between the observed and predicted concentrations in all of the systems investigated in this study and those reported previously. The values of equilibrium constants for the complexes determined from these data (Table 1) provided close agreement between the observed and predicted concentrations in all of the systems investigated in this study and those reported previously (e.g., see Figs. 3 and 4). 


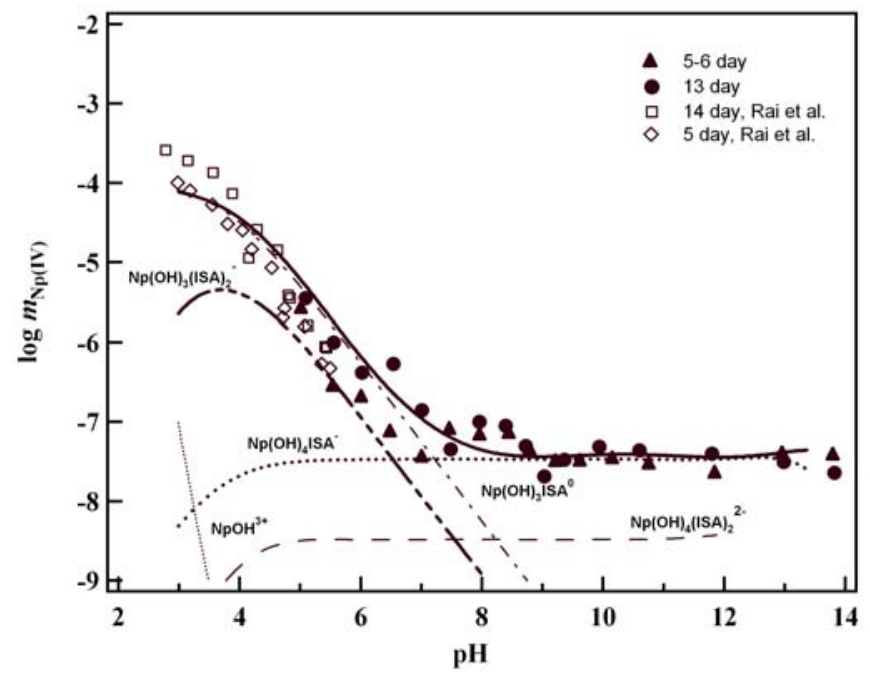

Fig.3. Aqueous $\mathrm{Np}(\mathrm{IV})$ concentrations in equilibrium with $\mathrm{NpO}_{2}$ (am) as a function of $\mathrm{pH}$ and at a fixed total ISA concentration of $0.0016 \mathrm{M}$. Relatively low-pH data from Rai et al. (1998b). Solid line represents total concentration, while other lines represent concentrations of different species, as identified, predicted using modeling parameters reported in Table 1.

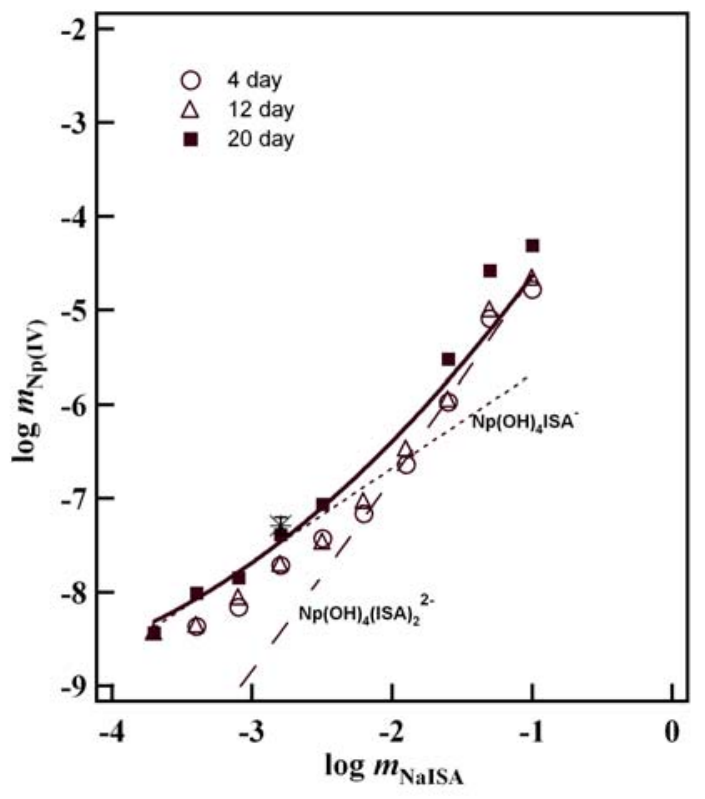

Fig. 4. Aqueous $\mathrm{Np}(\mathrm{IV})$ concentrations in equilibrium with $\mathrm{NpO}_{2}$ (am) as a function of time and NaISA concentrations at a fixed $\mathrm{pH}$ of $\sim 12$.

Solid line represents total concentrations, while other lines represent concentrations of different species, as identified, predicted using modeling parameters reported in Table 1. 
Table 1. Important Chemical Reactions Included in the Model.

\begin{tabular}{|c|c|c|}
\hline Reaction & $\log \mathrm{K}^{0}$ & Reference \\
\hline \multirow[t]{4}{*}{$\mathrm{Ca}(\mathrm{ISA})_{2}(\mathrm{c}) \rightleftharpoons \mathrm{Ca}^{2+}+2 \mathrm{ISA}^{-}$} & $-6.26 \pm 0.07$ & This Project \\
\hline & -6.54 & Van loon et al. (1999) \\
\hline & -7.62 & Rai et al. (1998a) \\
\hline & $-6.36 \pm 0.10$ & $\begin{array}{l}\text { Vercammen et al. } \\
\text { (1999) }\end{array}$ \\
\hline \multirow[t]{3}{*}{$\mathrm{Ca}^{2+}+\mathrm{ISA}^{-} \rightleftharpoons \mathrm{CaISA}^{+}$} & $1.44 \pm 0.07$ & This Project \\
\hline & 1.70 & Van loon et al. (1999) \\
\hline & 1.7 & $\begin{array}{l}\text { Vercammen et al. } \\
\text { (1999) }\end{array}$ \\
\hline \multirow[t]{2}{*}{$\mathrm{Ca}^{2+}+2 \mathrm{ISA}^{-} \rightleftharpoons \mathrm{Ca}(\mathrm{ISA})(\mathrm{aq})$} & $\mathrm{NN}$ & This Project ${ }^{\mathrm{a}}$ \\
\hline & 5.4 & Rai et al. (1998a) \\
\hline $\mathrm{ISL}(\mathrm{aq})+\mathrm{H}_{2} \mathrm{O} \rightleftharpoons \mathrm{ISA}^{-}+\mathrm{H}^{+}$ & $-3.64 \pm 0.07$ & This Project \\
\hline \multirow{2}{*}{$\mathrm{HISA}(\mathrm{aq}) \rightleftharpoons \mathrm{ISA}^{-}+\mathrm{H}^{+}$} & $-3.27 \pm 0.02$ & This Project ${ }^{\mathrm{b}}$ \\
\hline & -4.46 & Rai et al. (1998a) \\
\hline $\mathrm{Np}^{4+}+\mathrm{H}_{2} \mathrm{O} \rightleftharpoons \mathrm{NpOH}^{3+}+\mathrm{H}^{+}$ & -0.5 & Rai et al. (1999) \\
\hline \multirow[t]{2}{*}{$\begin{array}{l}\mathrm{NpO}_{2}(\mathrm{am})+\mathrm{ISA}^{-}+\mathrm{H}^{+}+\mathrm{H}_{2} \mathrm{O} \rightleftharpoons \\
\mathrm{Np}(\mathrm{OH})_{3} \mathrm{ISA}(\mathrm{aq})\end{array}$} & $2.57 \pm 0.37$ & This Project \\
\hline & 2.76 & Rai et al. (1998b) \\
\hline $\begin{array}{l}\mathrm{NpO}_{2}(\mathrm{am})+2 \mathrm{ISA}^{-}+\mathrm{H}^{+}+\mathrm{H}_{2} \mathrm{O} \rightleftharpoons \\
\mathrm{Np}(\mathrm{OH})_{3}(\mathrm{ISA})_{2}^{-}\end{array}$ & $4.68 \pm 0.37$ & This Project \\
\hline $\mathrm{NpO}_{2}(\mathrm{am})+\mathrm{ISA}^{-}+2 \mathrm{H}_{2} \mathrm{O} \rightleftharpoons \mathrm{Np}(\mathrm{OH})_{4} \mathrm{ISA}^{-}$ & $-4.76 \pm 0.37$ & This Project \\
\hline $\begin{array}{l}\mathrm{NpO}_{2}(\mathrm{am})+2 \mathrm{ISA}^{-}+2 \mathrm{H}_{2} \mathrm{O} \rightleftharpoons \\
\mathrm{Np}(\mathrm{OH})_{4}(\mathrm{ISA})_{2}^{2-}\end{array}$ & $-2.90 \pm 0.37$ & This Project \\
\hline \multicolumn{3}{|c|}{$\begin{array}{l}\text { This project in this column refers to the data presented in Rai et al. (2003), and } \\
\mathrm{NN}=\text { not needed. }\end{array}$} \\
\hline \multicolumn{3}{|c|}{$\begin{array}{l}\text { b Based on our NMR studies (Cho et al. 2003) and consistent with the solubility } \\
\text { studies on Ca(ISA) (c) (Rai et al. 2003). }\end{array}$} \\
\hline
\end{tabular}


Studies, similar to those described above for $\mathrm{Np}$, were also conducted on the solubility of $\mathrm{ThO}_{2}(\mathrm{am})$ as a function of $\mathrm{pH}$ at a fixed ISA concentrations, and as a function of ISA concentrations at different fixed $\mathrm{pH}$ values. The results show that the observed aqueous $\mathrm{Th}$ concentrations in the presence of ISA are up to many orders of magnitude higher than expected in the absence of ISA (Fig. 5), indicating that ISA will be effective in removing Th from contaminated surfaces in a large range of $\mathrm{pH}$ values. Although the solubility data shown in Fig. 4 were obtained at a fixed concentration of $0.08 \mathrm{M}$ ISA, the amount of Th solubilized will increase with the increase in ISA concentrations. To further develop the fundamental data and quantify ISA's ability to solubilize Th from contaminated surfaces, $\mathrm{ThO}_{2}(\mathrm{am})$ solubility was determined as a function of ISA concentrations and at fixed $\mathrm{pH}$ values of 6 and 12 (Fig. 6). These data show a dramatic increase in Th concentrations with the increase in ISA concentrations. These data (Fig. 5) also show that at the given ISA concentration, it is slightly more effective in solubilizing Th in the acidic region. Fundamental interpretations of these data to obtain information on the dominant aqueous species and values of thermodynamic equilibrium constants involving these species are in progress.

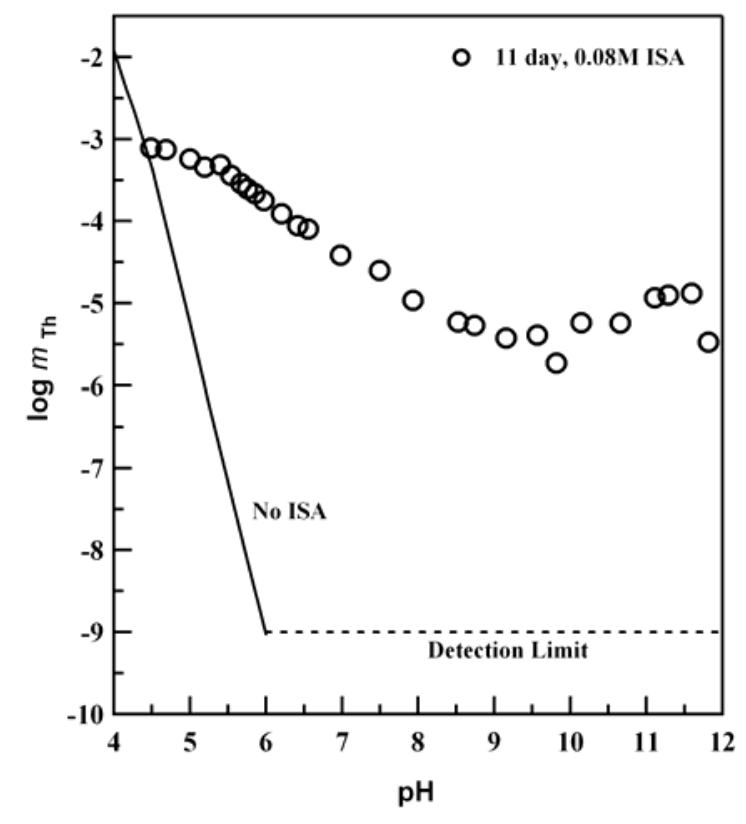

Fig. 5. Aqueous Th concentration in equilibrium with $\mathrm{ThO}_{2}(\mathrm{am})$ as a function of $\mathrm{pH}$ in the presence and absence of ISA. 


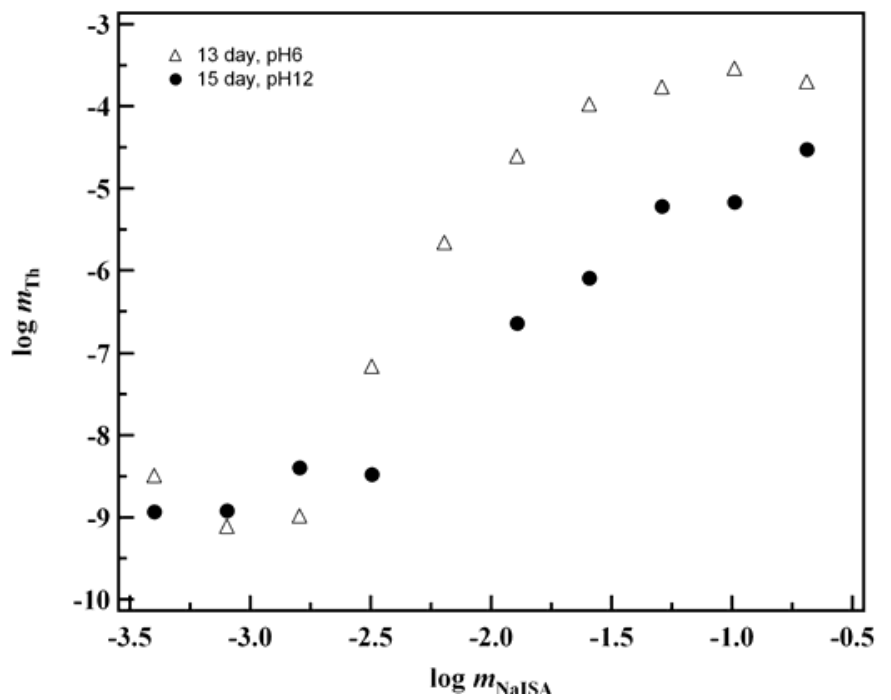

Fig. 6. Aqueous Th concentration in equilibrium with $\mathrm{ThO}_{2}(\mathrm{am})$ as a function of ISA concentrations and at a fixed $\mathrm{pH}$ values of 6 and 12 .

These fundamental data on $\mathrm{Np}(\mathrm{IV})$ and studies with Th are helping to develop a fundamental understanding of the ISA reactions in an environmentally important range of $\mathrm{pH}$ values and as a function of ISA concentrations such that chemical conditions necessary for foams and other media containing ISA for cleaning purposes can be well established based on scientific grounds.

\section{Isosaccharinate complexes with hexavalent actinides and important metal ions present in matrix of contaminated materials such as steel and concrete}

In order to determine the influence of metal ions (e.g., $\mathrm{Fe}(\mathrm{III})$ and $\mathrm{Ca}(\mathrm{II})$ ) on the extractability of actinides from contaminated surfaces, comprehensive thermodynamic data for ISA complexes with metal ions are required. We have developed comprehensive data for the $\mathrm{Ca}$ system, and have reported those results above. No data on ISA complexation with Fe(III) are available in the literature. Therefore, we have initiated studies with the Fe(III)-ISA system. We have preliminary data on the solubility of $\mathrm{Fe}(\mathrm{OH})_{3}$ (2-line ferrihydirte) in the absence and presence of $0.001 \mathrm{M}$ ISA as a function of $\mathrm{pH}$. These data show that ISA increases the solubility of Fe(III) (Fig. 7). Additional studies in this system are planned to develop a comprehensive thermodynamic model for this system. 


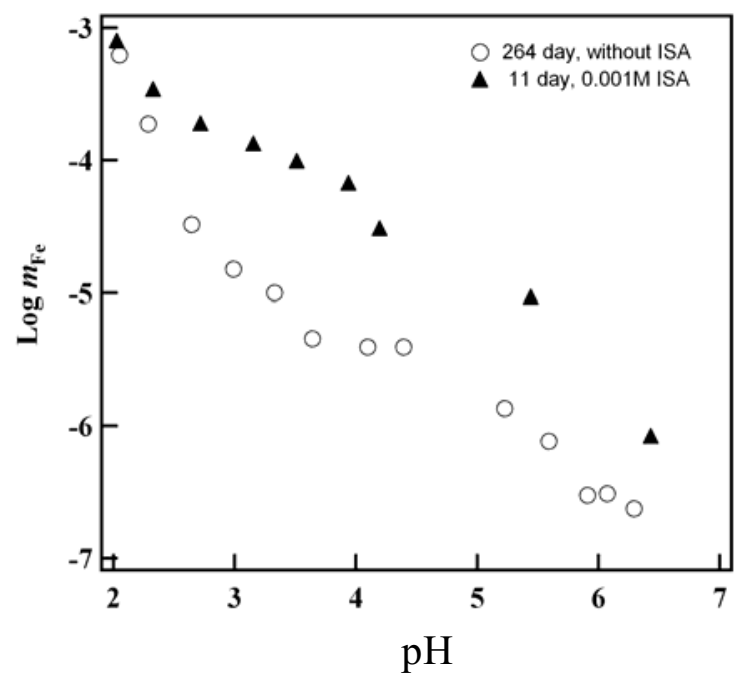

Fig. 7. Aqueous Fe(III) concentrations in equilibrium with $\mathrm{Fe}(\mathrm{OH})_{3}(2$-line ferrihydirte) in the absence and presence of ISA. Increase in ISA concentration will increase the solubility of Fe.

A combination of potentiometric and calorimetric titrations were performed to obtain the thermodynamic values for different ISA $\left(\mathrm{L}^{-}\right)$reactions with $\mathrm{H}^{+}, \mathrm{UO}_{2}{ }^{2+}$, and $\mathrm{Fe}^{3+}$. These data are summarized in Table 2. The stability constants of ISA complexes with different metal ions help to evaluate the effectiveness of ISA in decontamination, while the enthalpy values are useful in predicting the degree of complexation if the decontamination is conducted at temperatures other than the ambient.

Table 2. Thermodynamic parameters of isosaccharinate protonation and complexation with $\mathrm{U}(\mathrm{VI})$ and $\mathrm{Fe}(\mathrm{III}) . t=25^{\circ} \mathrm{C}, I=1.0 \mathrm{~mol} \mathrm{dm}^{-3}\left(\mathrm{NaClO}_{4}\right)$, the error limits represent $3 \sigma$.

\begin{tabular}{cccccc}
\hline Reaction & $\boldsymbol{j}$ & $\begin{array}{c}\log \boldsymbol{K}_{\mathbf{H}} \\
\operatorname{or~} \log \beta_{\mathrm{j}, \mathrm{M}}\end{array}$ & $\begin{array}{c}\Delta \boldsymbol{G}_{\boldsymbol{j}} \\
\mathrm{kJ} \mathrm{mol}^{1}\end{array}$ & $\begin{array}{c}\Delta \boldsymbol{H}_{\boldsymbol{j}} \\
\mathrm{kJ} \mathrm{mol}^{1}\end{array}$ & $\begin{array}{c}\Delta \boldsymbol{S}_{j} \\
\mathrm{~J} \mathrm{~K}^{-1} \mathrm{~mol}^{-1}\end{array}$ \\
\hline $\mathrm{H}^{+}+\mathrm{L}^{-}=\mathrm{HL}$ & & $3.65 \pm 0.05$ & -20.83 & $-7.94 \pm 0.03$ & $43 \pm 1$ \\
$\mathrm{UO}_{2}^{2+}+j \mathrm{~L}^{-}=\mathrm{UO}_{2} \mathrm{~L}_{\mathrm{j}}^{(2-\mathrm{j})^{+}}$ & 1 & $2.91 \pm 0.15$ & -16.61 & $-1.0 \pm 1.0$ & $52 \pm 4$ \\
& 2 & $5.37 \pm 0.07$ & -30.65 & $1.4 \pm 1.8$ & $108 \pm 6$ \\
& 3 & $7.25 \pm 0.18$ & -41.38 & $-6.2 \pm 3.0$ & $118 \pm 10$ \\
$\mathrm{Fe}^{3+}+j \mathrm{~L}^{-}=\mathrm{FeL}_{j}^{(3-\mathrm{j})+}$ & 1 & $5.06 \pm 0.17$ & -28.88 & $3.4 \pm 0.5$ & $108 \pm 4$ \\
& 2 & $8.51 \pm 0.15$ & -48.57 & $7.8 \pm 1.3$ & $189 \pm 5$ \\
& 3 & $11.00 \pm 0.16$ & -62.78 & $-18.3 \pm 2.0$ & $149 \pm 7$ \\
& 4 & $12.99 \pm 0.17$ & -74.13 & $-23.3 \pm 3.0$ & $170 \pm 10$ \\
\hline
\end{tabular}




\section{Proof-of-Principle Decontamination Tests Using ISA}

Studies at SNL focused on testing isosaccharinate for its effectiveness in removing actinides from contaminated surfaces and for preparing different formulations, such as foams and gels, for effective delivery of ISA to the contaminated surfaces. A set of preliminary tests of proof of principle were conducted using $\mathrm{U}(\mathrm{IV}), \mathrm{U}(\mathrm{VI})$, and $\mathrm{Pu}(\mathrm{IV})$. For uraium experiments $\mathrm{U}(\mathrm{IV})$ or U(VI) in solution was deposited on the steel surface by placing a drop of U solution on the steel coupons. The concentration of $U$ in each solution was $1 \times 10^{-6} \mathrm{M}$ at a $\mathrm{pH}$ of 6 . The solutions were allowed to dry on the surface and sit for 3 weeks prior to decontamination with deionized water, $0.04 \mathrm{M}$ ISA solution, or a $0.04 \mathrm{M}$ citrate solution. The coupons were placed in $50 \mathrm{ml}$. of the decontamination solutions and gently shaken. The results showed that ISA is much superior to citrate or plain water for removing uranium from the steel surfaces (Fig. 8).
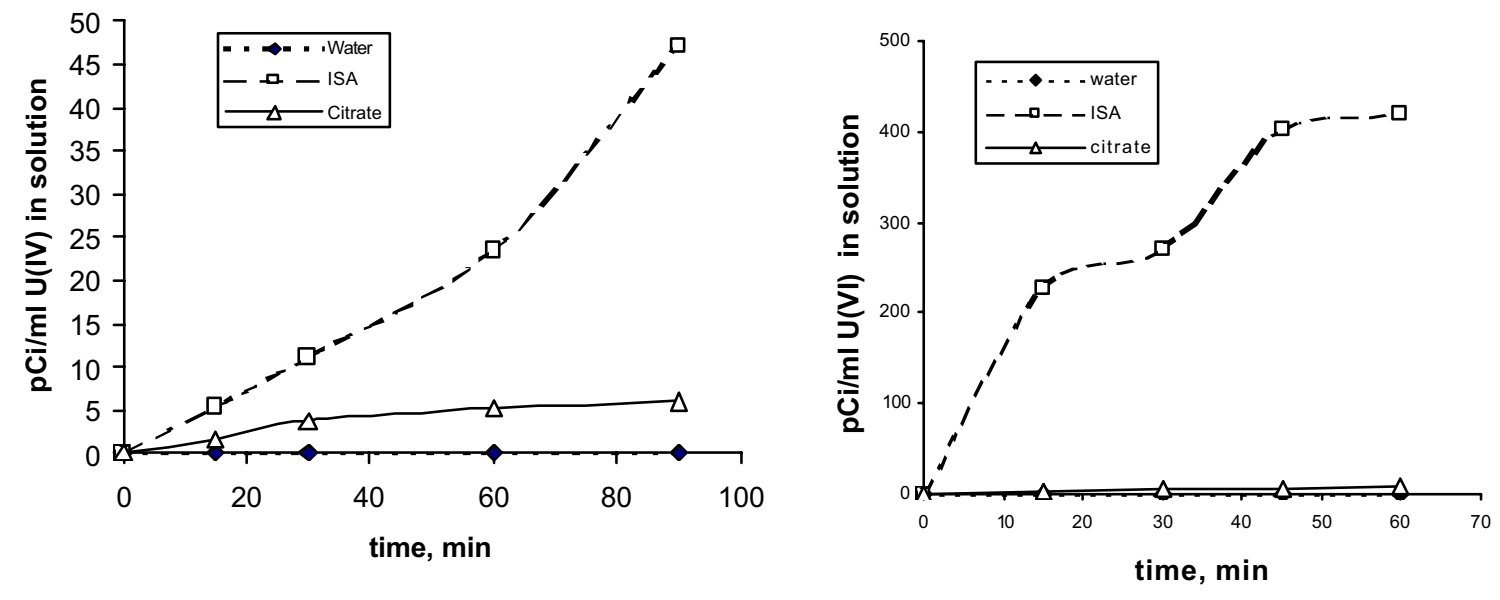

Fig. 8. Decontamination of U(IV) and U(VI) contaminated steel coupons using water, citrate solution and ISA solution.

Experiments with $\mathrm{Pu}$ were performed with $\mathrm{Pu}$ deposition on small pieces or ground up materials. These results indicated that decontamination of all material was enhanced by ISA (Table 3). With DI water only 3 to $12 \%$ of the Pu was desorbed. For pained wood $100 \%$ decontamination was observed. A blank with no added sorbate indicated $6 \%$ of the Pu sorbed to the container, but was removed upon addition of the ISA. Pu was added as $\mathrm{Pu}(\mathrm{IV})$, and no attempt was made to control the oxidation state of the $\mathrm{Pu}$. 
Table 3. Decontamination of Pu contaminated materials using sodium ISA. Experiments were performed with $5 \mathrm{~g}$ of material in $25 \mathrm{~mL}$ of water. After Pu sorption $0.15 \mathrm{~g}$ of sodium ISA was added to the mixtures and agitated for 24 hours.

\begin{tabular}{cccc}
\hline material & $\begin{array}{c}\text { Pu initial } \\
\text { conc., } \mathbf{p C i} / \mathbf{m L}\end{array}$ & \% Pu sorption & \% decontamination \\
\hline blank & $1.00 \mathrm{E}+05$ & 6 & 100 \\
marble & $1.00 \mathrm{E}+05$ & 89 & 25 \\
concrete & $1.00 \mathrm{E}+05$ & 99 & 22 \\
asphalt & $1.00 \mathrm{E}+05$ & 98 & 95 \\
steel & $1.00 \mathrm{E}+05$ & 68 & 83 \\
granite & $1.00 \mathrm{E}+05$ & 88 & 94 \\
wood & $1.00 \mathrm{E}+05$ & 45 & 111 \\
\hline
\end{tabular}

\section{PLANNED ACTIVITIES}

The main outputs from this project are the 1) fundamental data to evaluate the effectiveness of isosaccharinate for decontamination of actinides from steel and concrete surfaces and 2) development and testing of isosaccharinate containing foams/gels for worker safety and ease in decontamination. This is the last year of the three year project. The main emphasis of the project for the remaining time will be on completing the ongoing experimental studies and preparing technical reports/articles on studies that have already been completed.

\section{INFORMATION ACCESS}

The research conducted under this project has resulted in the following technical communications.

\section{Journal Articles}

Rao, L., A. Yu. Garnov, Dhanpat Rai, Y. Xia, R. C. Moore. 2004. Protonation and Complexation of Isosaccharinic Acid With U(VI) and Fe(III) in Acidic Solution: Potentiometric and Calorimetric Studies. Radiochimica Acta (in press)

Rai, Dhanpat, N. J. Hess, Y. Xia, L. Rao, H. M. Cho, R. C. Moore, Luc R. Van Loon 2003. Comprehensive Thermodynamic Model Applicable to Highly Acidic to Basic Conditions for Isosaccharinate Reactions with $\mathrm{Ca}(\mathrm{II})$ and $\mathrm{Np}(\mathrm{IV})$. Journal of Solution Chemistry 32: 665-689.

Cho, H. M., Dhanpat Rai, N. J. Hess, Y. Xia, and L. Rao. 2003. Acidity and Structure of Isosaccharinate in Aqueous Solution: A Nuclear Magnetic Resonance Study. Journal of Solution Chemistry 32: 691-702. 


\section{Technical Presentations}

Rai, Dhanpat, L. Rao, R. C. Moore. "Development of Biodegradable Isosaccharinate-containing Foams for Decontamination of Actinides". $226^{\text {th }}$ American Chemical Society national meeting, New York City, September 7-11, 2003,

Rao, L., A. Yu Garnov, Dhanpat Rai. 2003. Complexation of Uranium(VI) with Isosaccharinic Acid. Presentation at the $9^{\text {th }}$ International Conference on Chemistry and Migration Behavior of Actinides and Fission Products in the Geosphere. Gyeongju, South Korea, September 21-26, 2003.

Rai, Dhanpat, R. C. Moore, M. D. Tucker, L. Rao. 2001. Development of Biodegradable Isosaccharinate-Containing Foams for Decontamination of Actinides: Thermodynamic and kinetic Reactions Between Isosaccharinate and Actinides on Metal and Concrete Surfaces. Environmental Management Science Program, Deactivation \& Decommissioning, Kickoff Workshop for 2001 Awards. Oak Ridge National Laboratory, November 27-28.

Rai, Dhanpat, R. C. Moore, M. D. Tucker, and L. Rao. 2002. Development of Biodegradable Isosaccharinate-Containing Foams for Decontamination of Actinides: Thermodynamic and kinetic Reactions Between Isosaccharinate and Actinides on Metal and Concrete Surfaces. In: Science to Support DOE Site Cleanup: The Pacific Nothwest National Laboratory Environmental Management Science Program Awards. PNNL-13928, Pacific Northwest National Laboratory, Richland, WA, PP. 2.21 - 2.23.

Holt, K., R. C. Moore, M. Tucker, F. Salas. 2002. Use of an Isosaccharinate Containing Gel for Decontamination of Actinide Contaminated Surfaces. Presented at the Meeting of the American Chemical Society, Albuquerque, NM. November, 2002. 